\title{
Anti-Competitive Market Division Through Loyalty Discounts Without Buyer Commitment
}

\section{Citation}

Einer Elhauge \& Abraham L. Wickelgren, Anti-Competitive Market Division Through Loyalty Discounts Without Buyer Commitment (Harvard John M. Olin Discussion Paper Series, No. 723, Aug. 2012).

\section{Published Version}

http://www.law.harvard.edu/programs/olin_center/papers/pdf/Elhauge_723.pdf

\section{Permanent link}

http://nrs.harvard.edu/urn-3:HUL.InstRepos:30064216

\section{Terms of Use}

This article was downloaded from Harvard University's DASH repository, and is made available under the terms and conditions applicable to Other Posted Material, as set forth at http:// nrs.harvard.edu/urn-3:HUL.InstRepos:dash.current.terms-of-use\#LAA

\section{Share Your Story}

The Harvard community has made this article openly available.

Please share how this access benefits you. Submit a story.

\section{Accessibility}




\title{
HARVARD
}

JOHN M. OLIN CENTER FOR LAW, ECONOMICS, AND BUSINESS

\section{ANTI-COMPETITIVE MARKET DIVISION THROUGH LOYALTY DISCOUNTS WITHOUT BUYER COMMITMENT}

\author{
Einer Elhauge \\ Abraham L. Wickelgren \\ Discussion Paper No. 723 \\ $08 / 2012$ \\ Harvard Law School \\ Cambridge, MA 02138
}

This paper can be downloaded without charge from:

The Harvard John M. Olin Discussion Paper Series: http://www.law.harvard.edu/programs/olin_center/

The Social Science Research Network Electronic Paper Collection:

http://ssrn.com/ 


\title{
Anti-Competitive Market Division Through Loyalty Discounts Without Buyer Commitment
}

\author{
Einer Elhauge and Abraham L. Wickelgren ${ }^{1}$ \\ Harvard University \& University of Texas at Austin/Yale \\ University
}

August 1, 2012

(C)2011-12 Einer Elhauge and Abraham L. Wickelgren. All rights reserved.

\begin{abstract}
We show that loyalty discounts without buyer commitment create an externality among buyers because each buyer who signs a loyalty discount contract softens competition and raises prices for all buyers. This externality can enable an incumbent to use loyalty discounts to effectively divide the market with its rival and raise prices. We prove that, provided the entrant's cost advantage is not too large, with enough buyers, this externality implies that in any equilibrium some buyers sign loyalty discount contracts, segmenting the market and reducing consumer welfare and total welfare. These propositions are true even if the buyers coordinate, the entrant is more efficient, the loyalty discounts cover less than half the market, and all the loyalty discounts are above cost. We also prove that these propositions hold even if we assume no economies of scale, no downstream competition, no buyer switching costs, no financial constraints, no limits on rival expandability, and no intraproduct bundle of contestable and incontestable demand.
\end{abstract}

JEL: C72, K0, K21, L12, L40, L41, L42

1 Email: Elhauge@law.harvard.edu and awickelgren@law.utexas.edu. We thank seminar participants at the University of Florida, Northwestern, Stanford and the Washington University conference on Theoretical Law and Economics. Elhauge has consulted on loyalty discount cases for both plaintiffs and defendants, with most of the cases being for plaintiffs. 


\section{Introduction}

The issue of how to treat loyalty discounts has split both the courts and scholars. Courts disagree about whether loyalty discounts should be deemed anticompetitive only when they are below cost. ${ }^{1}$ Scholars are likewise divided. ${ }^{2}$

Part of this disagreement reflects a underlying dispute about how to treat loyalty discounts even they include buyer commitments like in excusive dealing. In a companion paper, we show that loyalty discounts with buyer commitment have stronger anticompetitive effects than simple exclusive dealing. (Elhauge and Wickelgren 2012). In this paper, we instead assess loyalty discounts without any buyer commitment, which leave the buyer free to buy elsewhere if a rival offers a lower price.

Many have analogized loyalty discounts to predatory pricing, especially when the loyalty discount involves no buyer commitment. But even without buyer commitment, loyalty discounts have a crucial difference from ordinary predatory pricing: loyalty discounts involve a seller commitment to charge loyal buyers less than disloyal buyers.

We show that, even without any buyer commitment, this seller commitment creates distinctive anticompetitive effects that can make loyalty discounts more akin to market division than to predatory pricing. The reason is that loyalty discounts effectively divide the market between buyers with a loyalty discount and those without. Because the loyalty discount requires the seller to charge loyal buyers less than buyers who are not covered by the loyalty discount, the seller cannot lower prices to uncovered buyers without also lowering prices to loyal buyers. This makes it more costly for the seller to compete for uncovered buyers and effectively cedes those buyers to the entrant, which reduces the entrant's incentive to compete aggressively for buyers covered by the loyalty discount. The reduced competition leads to higher consumer prices and lower total welfare.

\footnotetext{
${ }^{1}$ Compare, e.g., Concord Boat v. Brunswick Corp., 207 F.3d 1039, 1061-62 (8th Cir. 2000) (must be below cost), with LePage's v. 3M, 324 F.3d 141, 147-52 (3d Cir. 2003) (en banc) (need not be).

${ }^{2}$ For articles arguing that, like predatory pricing, loyalty discounts presumptively lower prices and cannot harm consumer welfare in the long run unless they are below cost, see Hovenkamp (2005); Lambert (2005); Hovenkamp (2006). For scholarship arguing that loyalty discounts without buyer commitment can create anticompetitive effects similar to exclusive dealing, see Tom, et al., pp. 615, 623-24, 627 (2000); Elhauge, pp. 284-92 (2003); Spector, pp. 99-101 (2005); Whinston, p. 166 (2006); Kaplow \& Shapiro, pp. 1203 n.98 \& 106 n.207, 1212 n.221 (2007); Elhauge, pp. 407-408 (2008).
} 
We prove that as long as the entrant's cost advantage is not too large and there are at least three buyers, loyalty discounts without buyer commitment will soften competition and increase prices above competitive levels, although they cannot completely exclude the entrant from the market. If the entrant and the incumbent choose prices simultaneously or if the incumbent acts as a Stackelberg-leader, the incumbent will never cover more than half the buyers using loyalty discounts without buyer commitment and both the entrant and the incumbent will have positive market-share with positive probability. Thus, loyalty discounts without buyer commitment can also be anticompetitive even if they cover a minority of buyers. Further, these anticompetitive effects can result even if buyers coordinate, the entrant is more efficient, and all loyalty discounts are above cost.

Some past scholarship has argued that loyalty discounts without buyer commitment can have effects similar to exclusive dealing. ${ }^{3}$ However, those underlying exclusive dealing effects themselves generally assume economies of scale and intermediary buyers who compete downstream. ${ }^{4}$ In contrast, the model here demonstrates an anticompetitive effect that can result without any economies of scale and even with buyers who are final consumers rather than intermediary competitors. Some have also concluded that loyalty discounts without buyer commitment can create anticompetitive effects when there exist switching costs, financial constraints, limits on rival expandability, or buyer demand that is segmented into contestable and incontestable portions that can be effectively bundled by the loyalty discount. ${ }^{5}$ Our analysis shows that those assumptions are unnecessary to show anticompetitive effects given the seller commitment used in loyalty discounts.

The phenomenon identified here also differs sharply from price-matching clauses or most favored nation clauses. Although such clauses also involve seller pricing commitments, they do not involve seller commitments to charge loyal buyers less than other buyers. Pricematching clauses instead involve seller commitments to match rival prices. Loyalty discounts

\footnotetext{
${ }^{3}$ See supra note 2 .

${ }^{4}$ Rasmusen et al. (1991) and Segal and Whinston (2000) assumed economies of scale. Simpson \& Wickelgren (2007) found anticompetitive effects from exclusive dealing without economies of scale, but only with intermediary buyers who compete with each other.

${ }^{5}$ Ordover and Shaffer (2007); Elhauge, pp. 411-412 (2011). Marx and Shaffer (2004) and Kolay et al. (2004) also examine market-share and all-units discounts, but without considering the effects of a seller commitment to maintain a loyalty discount.
} 
involve no such seller commitment to match. Indeed, loyalty discounts have the opposite effect of discouraging sellers from matching rival prices for uncovered buyers. Most-favorednations clauses involve seller commitments to charge agreeing buyers no more than the seller charges other buyers. In contrast, loyalty discounts involve seller commitments to charge agreeing buyers affirmatively less than the seller charges other buyers. We find that the optimal loyalty discount for the incumbent typically exceeds zero. Further, we find that loyalty discounts have anticompetitive effects under very different conditions than are assumed in the literature on most-favored nation clauses. Most articles on most favored nations clauses have found anticompetitive effects because they assumed oligopolistic coordination, see Cooper (1986), or because they assumed a monopolist selling a durable good that might use such clauses to restrain competition by itself later in time, Butz (1990); Marx \& Shaffer (2004). None of those assumptions is necessary to show anticompetitive effects from loyalty discounts under the model offered here. Indeed, we find that loyalty discounts can have anticompetitive effects even in a one-shot game setting. ${ }^{6}$

Our paper is most similar to Elhauge (2009), which also analyzed loyalty discounts without commitment. However, this paper has some important differences that generate different and more general results. First, his article assumes linear demand and does not allow the potential entrant to be more efficient than the incumbent seller. Our results are more general because we prove our basic results without imposing any specific functional form on buyer demand (other than weak concavity), and we allow the rival's marginal cost to be less than the incumbent's.

Second, our analysis of loyalty discounts without buyer commitment differs from Elhauge (2009) in several ways that changes the results. (A) He assumed that buyers will always accept loyalty discounts that do not bind the buyers. We show that this assumption is mistaken. Because loyalty discounts affect the pricing strategy of both the incumbent and the entrant, buyers might not want to accept loyalty discounts without compensation, even without any buyer commitment. By explicitly modeling buyer acceptance decisions, we

\footnotetext{
${ }^{6}$ Hviid and Shaffer (2010) find that a most favored nation clause can have anti-competitive effects in a one-shot game if it is combined with a price-matching clause. Loyalty discounts have this effect without including price-matching.
} 
are able to determine more accurately the conditions under which the incumbent can use loyalty discounts to elevate market prices without any buyer commitment. (B) Elhauge never formally analyzed the fraction of buyers that the incumbent would cover without economies of scale, offering instead the conjecture that it would be all but one buyer. We formally analyze the optimal fraction of buyers to whom the incumbent will offer these discounts, showing that with either simultaneous pricing or an incumbent who prices first, the optimal fraction is in fact always less than half. This distinction has important policy relevance because it means that loyalty discounts without buyer commitment can, without economies of scale, have anticompetitive effects even when they cover a minority of the market. (C) Because he does not analyze the optimal fraction of buyers that will be covered, he does not correctly establish the prices that will be paid. We show that while loyalty discounts without buyer commitment do enable the incumbent to take market share from a more efficient entrant and elevate prices above the competitive level, they do not lead to monopoly pricing with certainty, contrary to Elhauge (2009).

Our paper proceeds as follows. Section 2 outlines the model. Section 3 considers the case in which the entrant chooses price first. Section 4 analyzes the case in which the incumbent is a Stackelberg price leader. Section 5 examines simultaneous pricing. Section 6 concludes. Proofs not in the text are in the appendix.

\section{Model}

An incumbent firm, $I$, produces a good at constant marginal cost, c. A potential entrant, $E$, can produce this same good at marginal cost, $c_{e}<c$. We assume, to highlight the anticompetitive effects of loyalty discounts, that $E$ incurs no fixed cost to enter the market. Thus, unlike most exclusive dealing or predatory pricing models, we do not assume economies of scale or entry costs. There are $N$ buyers for the good. Each buyer's demand function is given by $q(p), q^{\prime}<0, q^{\prime \prime} \leq 0$. Let $p^{m}=\arg \max _{p}(p-c) q(p)$; that is, $p^{m}$ is $I$ 's profitmaximizing monopoly price. Let $p_{e}^{m}=\arg \max _{p}\left(p-c_{e}\right) q(p)$; that is, $p_{e}^{m}$ is E's profitmaximizing monopoly price.

Let $s(p)$ be a buyer's consumer surplus from buying $q(p)$ of the good at price $p . s(p)=$ 
$\int_{p}^{\infty} q(x) d x$. We make the following assumption about the maximum size of the entrant's cost advantage:

Assumption $(*)\left(p^{m}-c\right) q\left(p^{m}\right)>s\left(p_{e}^{m}\right)-s\left(p^{m}\right)$

Assumption (*) means that incumbent's profit from being a monopolist exceeds the increase in consumer surplus that results when buyers purchase at the entrant's monopoly price rather than the incumbents. Because the entrant's monopoly price depends on $c_{e}$, this simply requires that $c_{e}$ is not too far below $c$.

We have four periods in our model, which we label period 1, period 1.5, period 2, and period 3. In period 1 , the incumbent offers a loyalty discount sequentially to buyers of the form $\{d, t\}$ in which buyers agree to be eligible for the discount of $d$ off the price that $I$ offers to buyers who do not sign the contract in exchange for a transfer of $t$ from $I$ to the buyer. $^{7}$ Buyers sequentially decide whether or not to accept this offer in period 1 . Those who accept have the option to buy from either the incumbent or the entrant in period 3 , but they only receive the discount if they buy from the incumbent. Those who are not offered the discount or do not accept it can also buy from either firm but receive no discount if they buy from the incumbent. Thus, for any price $p_{f}$ that the incumbent offers to free buyers (i.e., those not covered by a loyalty discount), the covered buyers (i.e, those who accepted the loyalty discount) receive a price of $p_{f}-d$ in period 1. Let $\theta$ be the share of buyers who agree to the loyalty discount in period 1. (In the interest of reducing notation, we ignore integer constraints on the number of buyers covered.)

In period 1.5, $E$ decides whether to enter the market or not. In period 2, $E$ (if active) and $I$ set prices to uncovered buyers of $p_{e}$ and $p_{f}$ respectively (resulting in an $I$ price to covered buyers of $p_{f}-d$ if they remain loyal to $I$ and $p_{f}$ if they instead buy from E). If $\theta=0$, then there are, in effect, no loyalty discounts. In that case, because $E$ and $I$ produce

\footnotetext{
${ }^{7}$ Notice, we do not allow $I$ to commit to a price at this time. This could be because the good is hard to describe in period 1. It could be because the cost of production is not precisely known in period 1 (our model could easily accomodate a common shock to production costs). Also, as we discuss in the conclusion, committing to a price rather than a loyalty discount is not as profitable for the incumbent. Thus, agreeing to a loyalty discount simply means that the buyer receives a discount from the price (often called a "list price") offered to buyers who did not agree to a loyalty contract.
} 
identical products, we have the standard Bertrand result that $E$ captures the entire market at a price of $p_{e}=c$. In period 3, buyers make purchase decisions.

Suppose that $E$ enters in period 1.5 and $I$ and $E$ set prices $p_{f}$ and $p_{e}$ respectively in period 2. In period 3 , if $p_{f}-d<p_{e} \leq p_{f}$, then the uncovered buyers all purchase from $E$, and the covered buyers all purchase from $I .{ }^{8}$ Thus, $I$ 's profit is $\theta\left(p_{f}-d-c\right) q\left(p_{f}-d\right)$, while $E$ 's profit is $(1-\theta)\left(p_{e}-c_{e}\right) q\left(p_{e}\right)$. If $p_{e}>p_{f}$, then all buyers purchase from $I$. Thus, $I$ 's profit is $\theta\left(p_{f}-d-c\right) q\left(p_{f}-d\right)+(1-\theta)\left(p_{f}-c\right) q\left(p_{f}\right)$ while $E$ 's profit is zero. If $p_{f}-d \geq p_{e}$, then all buyers purchase from $E$, and thus $E$ 's profit is $\left(p_{e}-c_{e}\right) q\left(p_{e}\right)$ and $I$ 's profit is zero.

In the following sections, we consider separately the cases in which the entrant chooses its price first, the incumbent chooses its price first, and simultaneous pricing.

\section{Entrant Chooses Price First}

If the entrant chooses a price $p_{e}$, then the incumbent will either choose $p_{f}=p_{e}-\varepsilon$ and sell to the entire market or it will choose $p_{f}=p_{e}+d-\varepsilon$ and sell only to covered buyers. Letting $\varepsilon \rightarrow 0$, we have that the incumbent sells only to covered buyers if and only if the following holds:

$$
\theta\left(p_{e}-c\right) q\left(p_{e}\right)-\left\{\theta\left(p_{e}-d-c\right) q\left(p_{e}-d\right)+(1-\theta)\left(p_{e}-c\right) q\left(p_{e}\right)\right\} \geq 0
$$

Clearly, the entrant would never choose a price for which this condition does not hold, because then it would earn zero profits. The left hand side is decreasing in $p_{e}$ as long as profits are concave in prices and $p_{e}<p^{m}$. Furthermore, the left hand side is clearly positive at $p_{e}=c$ for any $d>0$. Thus, the incumbent will sell only to covered buyers so long as the entrant chooses a small enough price (which can exceed $c$ ). If the discount is large enough, it is possible that the incumbent will sell only to covered buyers even if $p_{e}=p_{e}^{m}$. Let $\overline{p_{e}}$ be the price that satisfies (1) at equality if it exists and is smaller than $p_{e}^{m}$, or alternatively, $p_{e}^{m}$.

By totally differentiating (1) with respect to $\theta$, we can determine how $\overline{p_{e}}$ varies with $\theta$

\footnotetext{
${ }^{8}$ Notice, we make the standard tie-breaking assumption that if both firms charge the identical price, then buyers buy from the lower cost firm ( $E$ in this case). This assumption makes the analysis of the standard Bertrand equilibrium less cumbersome since the equilibrium price is simply the cost of the higher cost firm rather than some epsilon below that level.
} 
for $\overline{p_{e}}<p_{e}^{m}$ :

$$
\frac{d \overline{p_{e}}}{d \theta}=\frac{2\left(\overline{p_{e}}-c\right) q\left(\overline{p_{e}}\right)-\left(\overline{p_{e}}-d-c\right) q\left(\overline{p_{e}}-d\right)}{(1-2 \theta)\left\{q\left(\overline{p_{e}}\right)+\left(\overline{p_{e}}-c\right) q^{\prime}\left(\overline{p_{e}}\right)\right\}+\theta\left\{q\left(\overline{p_{e}}-d\right)+\left(\overline{p_{e}}-d-c\right) q^{\prime}\left(\overline{p_{e}}-d\right)\right\}}>0
$$

This is positive for $\theta<1 / 2$ because the incumbent's profit is greater at $\overline{p_{e}}$ than $\overline{p_{e}}-d$ because $\overline{p_{e}} \leq p_{e}^{m}$ and because the incumbent's profit is increasing at both $\overline{p_{e}}$ and $\overline{p_{e}}-d$. Thus, for $\theta<1 / 2$ (and for larger $\theta$ we can see that $\overline{p_{e}}=p_{e}^{m}$ ), $\overline{p_{e}}$ is increasing in $\theta$. That is, the higher the share of buyers covered by the loyalty discount, the higher the price the entrant can choose without the incumbent undercutting this price for uncovered buyers (which would eliminate the entrant's profit). Thus, (1) implicitly defines $\overline{p_{e}}$ as a non-decreasing (strictly increasing when $\overline{p_{e}} \leq p_{e}^{m}$ ) function of $\theta$.

The entrant can also choose $p_{e}=c$ and sell to all buyers. It will prefer to choose $\overline{p_{e}}$ if and only if:

$$
(1-\theta)\left(\overline{p_{e}}-c_{e}\right) q\left(\overline{p_{e}}\right)-\left(c-c_{e}\right) q(c) \geq 0
$$

Clearly, this is only satisfied if $\theta$, the fraction of covered buyers, is not too large.

The entrant will never choose a price higher than $p_{e}^{m}$. To see if loyalty discounts without commitment can support this price, note that (2) implies a maximum theta of $\bar{\theta}=\frac{\left(p_{e}^{m}-c_{e}\right) q\left(p_{e}^{m}\right)-\left(c-c_{e}\right) q(c)}{\left(p_{e}^{m}-c_{e}\right) q\left(p_{e}^{m}\right)}$. Next, we see if we can satisfy (1) at $\bar{\theta}$. If the entrant's innovation satisfies Assumption $(*)$ (so that $p_{e}^{m}>c$ ), then $\bar{\theta}>0$. If there is no restriction on $d$ and $\theta>0$, (1) can always be satisfied because the incumbent's loss from selling to even one covered buyer at a price of $p_{e}-d$ can be made arbitrarily large by making $d$ arbitrarily large (so that the incumbent has to pay the covered buyer an arbitrarily large amount to buy the good).

Alternatively, one might imagine that $p_{e}-d$ must be non-negative (the incumbent cannot offer a negative price to covered buyers) or that $p_{e}-d \geq c$ (the incumbent cannot price below cost to covered buyers). If we impose the first constraint, then loyalty discounts can support the entrant choosing $p_{e}^{m}$ if and only if:

$$
(2 \bar{\theta}-1)\left(p_{e}^{m}-c\right) q\left(p_{e}^{m}\right)+\bar{\theta} c q(0) \geq 0
$$


The reason is that if this inequality is satisfied, then the incumbent earns more profit from selling only to covered buyers at the entrant's monopoly price than it would earn from selling to uncovered buyers at the entrant's monopoly price and selling to covered buyers at a price of zero (which would give it losses of $c q(0)$ ). The left hand side of this is increasing in $\theta$. This is clearly satisfied for any $\bar{\theta} \geq 1 / 2$ and could be satisfied for much lower $\bar{\theta}$ if the incumbent's losses at a price of zero are substantial. If we impose the second constraint (no predatory pricing), then loyalty discounts can support the entrant choosing $p_{e}^{m}$ if and only if $\bar{\theta} \geq 1 / 2$. Let $\hat{\theta}=\frac{\left(p_{e}^{m}-c\right) q\left(p_{e}^{m}\right)}{2\left(p_{e}^{m}-c\right) q\left(p_{e}^{m}\right)+c q(0)}$. We have now proven the following lemma.

Lemma 1 If the discounted price must be non-negative, then loyalty discounts without buyer commitment can support an entrant price of $p_{e}^{m}$ if $\theta \in[\hat{\theta}, \bar{\theta}]$. If the discounted price cannot be below c, then loyalty discounts without buyer commitment can support an entrant price of $p_{e}^{m}$ if $\theta \in[1 / 2, \bar{\theta}]$. In either case, the incumbent just undercuts $p_{e}^{m}$ to covered buyers and does not sell to uncovered buyers.

It remains to be seen whether or not the incumbent can induce this fraction of buyers to agree to be covered by a loyalty discount. While one might think that this is trivial because agreeing to the discount involves does not bind a buyer, this is does not mean that agreeing is necessarily costless to the buyer. As the fraction of covered buyers increases, as long as it is below $\hat{\theta}$ or $1 / 2$, the greater is the price the entrant will choose. Because the incumbent chooses a price so that the discounted price just undercuts the entrant's price, this means that agreeing to be covered by the discount can increase the price the buyer expects to pay if the buyer expects that enough other buyers will choose not to be covered by the discount. In this case, the incumbent might have to pay buyers to induce them to be covered.

Whether this will be possible will depend on the number of buyers and the entrant's cost advantage. If there are only two buyers, for example, then buyers will never agree to be covered by loyalty discounts without buyer commitment for any up-front payment that the incumbent would be willing to make. The incumbent would never want to cover both buyers because then the entrant would have to charge $c$ to stop the incumbent from undercutting it. If the incumbent signs up only one buyer, then this buyer loses consumer surplus because of the higher price, but the incumbent only gains from the higher price through sales to this one 
buyer. Because elevating prices above costs is inefficient (increased profits are less than lost consumer surplus), the incumbent cannot pay one buyer to accept. With only one covered buyer, there is no negative externality on other buyers that the incumbent can benefit from (there is a negative externality, but this benefits the entrant who sells to the uncovered buyer at a higher price). With more buyers, however, it is possible for the incumbent to profitably induce enough buyers to sign the loyalty discount contract so that prices are elevated to $p_{e}^{m}$ as long as the entrant's cost advantage is not too great.

Proposition 1 (A) If there is no constraint on $d$, then the incumbent can induce $\bar{\theta} N$ buyers to be covered by a loyalty discount without buyer commitment in exchange for an arbitrarily small payment if $\bar{\theta} N \geq \operatorname{Max}\left\{2, \frac{s(c)-s\left(p_{e}^{m}\right)}{\left(p_{e}^{m}-c\right) q\left(p_{e}^{m}\right)}\right\}$ leading to $p_{e}=p_{e}^{m}$ and $p_{f}-d=$ $p_{e}^{m}-\varepsilon$. (B) If the discounted price is constrained to be non-negative, then the incumbent can induce $\bar{\theta} N$ buyers to be covered by a loyalty discount without buyer commitment in exchange for an arbitrarily small payment if $\bar{\theta} N \geq \operatorname{Max}\left\{\hat{\theta} N, \frac{\hat{\theta} N\left(s(c)-s\left(p_{e}^{m}\right)\right)}{\left(p_{e}^{m}-c\right) q\left(p_{e}^{m}\right)}\right\}$. This condition will always be met if demand is concave and the entrant's cost advantage is sufficiently small. When this condition is met, prices will be $p_{e}=p_{e}^{m}$ and $p_{f}-d=$ $p_{e}^{m}-\varepsilon$. (C) If the discounted price is constrained to not be below $c$, then the incumbent can induce $\bar{\theta} N$ buyers to be covered by a loyalty discount without buyer commitment in exchange for an arbitrarily small payment if $\bar{\theta} N \geq \operatorname{Max}\left\{N / 2, \frac{N\left(s(c)-s\left(p_{e}^{m}\right)\right)}{2\left(p_{e}^{m}-c\right) q\left(p_{e}^{m}\right)}\right\}$. This condition will always be met if demand is concave and the entrant's cost advantage is sufficiently small. When this condition is met, prices will be $p_{e}=p_{e}^{m}$ and $p_{f}-d=$ $p_{e}^{m}-\varepsilon$.

Proof. See Appendix

If the incumbent can offer an arbitrarily large discount, then the incumbent never wants to sell to both covered and uncovered buyers because charging a price that meets the entrant's price for uncovered buyers will result in arbitrarily large losses from selling to each covered buyer. Thus, having one covered buyer is sufficient to ensure that prices are at the entrant's monopoly price. So, once the incumbent has signed up one buyer, all remaining buyers expect to pay the entrant's monopoly price whether they are covered or not. Hence they will sign up for a trivial side-payment. In order to ensure that one buyer will sign up, the 
incumbent has to be willing to pay that one buyer her loss of consumer surplus from paying the monopoly price rather than the competitive price. But, if it is profitable to do so, the incumbent need not actually pay this amount because buyers prior to $N-\bar{\theta} N$ expect the incumbent to offer buyer $N-\bar{\theta} N$ her lost consumer surplus to sign $\left(s(c)-s\left(p_{e}^{m}\right)\right)$, so they might as well sign for any amount.

If the incumbent's discount is constrained so that it cannot offer a negative price, then its loss per covered buyer is bounded, hence it needs to sign up more buyers to ensure it does not have an incentive to undercut the entrant's price of $p_{e}^{m}$. To eliminate an equilibrium in which all buyers reject being covered thinking that all subsequent buyers will reject, the incumbent has to be able to reimburse $\hat{\theta} N$ buyers for their loss in consumer surplus out of the profits of selling to $\bar{\theta} N$ covered buyers at the entrant's monopoly price. The buyers' loss in consumer surplus is less than $s(c)-s\left(p_{e}^{m}\right)$ each. ${ }^{9} \quad$ Thus, if $\bar{\theta} N \pi^{p_{e}^{m}}-\hat{\theta} N\left(s(c)-s\left(p_{e}^{m}\right)\right)>0$, the incumbent always has a credible threat to sign up a sufficient number of buyers.

One might think that this is easier to satisfy as the entrant's costs are smaller because the lost consumer surplus is smaller. However, smaller entrant costs also reduce $\bar{\theta}$, the maximum fraction of buyers that can be covered without the entrant charging $c$ and selling to all buyers. It turns out that this latter effect matters more when the entrant's innovation is close to drastic $\left((8)\right.$ is decreasing in $c_{e}$ when $c_{e}$ is such that $\left.p_{e}^{m}=c\right)$. But, if the entrant's costs are close to the incumbent's ${ }^{10}$ and demand is concave, then the incumbent can always induce enough buyers to agree to be covered for a trivial side-payment, leading the market to be divided between the incumbent and the entrant, with all buyers paying the entrant's optimal monopoly price. Thus, even without committing buyers to buy only from the incumbent, if the entrant prices first, loyalty discounts can lead to a divided market and higher prices.

\footnotetext{
${ }^{9}$ If the first buyer to sign believes that her signing will induce all the others to sign, but that none will sign if she does not, then her lost consumer surplus from signing is exactly $s(c)-s\left(p_{e}^{m}\right)$. All subsequent buyers have a smaller lost consumer surplus since even if all later buyers reject, the price will be elevated above $c$ due to the earlier buyers being covered. Thus, $s(c)-s\left(p_{e}^{m}\right)$ is an upper bound on the lost consumer surplus per buyer.

${ }^{10}(8)$ is increasing in $c_{e}$ at $c_{e}=c$, so satisfying this condition becomes harder as $c_{e}$ falls from $c$.
} 


\section{Incumbent Chooses Price First}

If the incumbent chooses its price to free buyers, $p_{f}$, first, then the entrant will either choose to price at $p_{e}=\operatorname{Min}\left\{p_{f}, p_{e}^{m}\right\}$-selling only to uncovered buyers-or the entrant will choose $p_{e}=\operatorname{Min}\left\{p_{f}-d, p_{e}^{m}\right\}$ and sell to all buyers. Because the incumbent makes zero profit in the latter case, for any given fraction of covered buyers, $\theta$, the incumbent must choose a price $p_{f}$ such that the entrant prefers to sell only to uncovered buyers. That is, $p_{f}$ must satisfy:

$$
(1-\theta)\left(p_{f}-c_{e}\right) q(p)-\left(p_{f}-d-c_{e}\right) q\left(p_{f}-d\right) \geq 0
$$

Unlike when the entrant chooses price first, here the left hand side of (4) is decreasing in $\theta$, which means that the $p_{f}$ that satisfies (4) at equality is decreasing in $\theta$. Furthermore, notice that if (4) holds, covered buyers pay $p_{f}-d$ while uncovered buyers pay $\operatorname{Min}\left\{p_{f}, p_{e}^{m}\right\}$. Thus, unlike when the entrant prices first, here agreeing to be covered is a dominant strategy for buyers as long as one buyer will be covered. Whether or not the incumbent must pay to cover one buyer if all other buyers have rejected being covered depends on the pricing equilibrium with no covered buyers. With no covered buyers, the incumbent earns zero for any price $p_{f} \geq c$ and loses money on any lower price. Thus, there is no unique equilibrium with no covered buyers: buyers could face any price between $c$ and $p_{e}^{m}$ because the incumbent has zero sales and profits for any price in this region. ${ }^{11}$ It will be the most difficult for the incumbent to get buyers to agree to be covered by a loyalty discount if they believe the equilibrium with no covered buyers will result in a price of $c$. In that case, the incumbent would have to be willing to pay one buyer compensation. But, if buyers believe the incumbent will do that, then all buyers will agree to be covered for no compensation because they expect at least one covered buyer and they pay lower prices if they sign up both because covered buyers pay less than uncovered ones and because both prices are lower when there are more covered buyers.

Thus, the incumbent can certainly cover any fraction of buyers at no cost so long as it could profitably compensate one buyer for its lost consumer surplus (and possibly without

\footnotetext{
${ }^{11}$ We do not necessarily get the Bertrand equilibrium since (unlike with simultaneous pricing), the entrant will adjust its price based on the incumbent's to ensure the incumbent has zero sales for any price above $c$.
} 
needing to be able to profitably compensate any buyers). Ignoring the cost of compensating one buyer, the incumbent's profit from covering a fraction, $\theta$, of buyers is $\theta\left(p_{f}-d-c\right) q\left(p_{f}-d\right)$ where $p_{f}$ and $d$ must be such that (4) holds. If we assume there are no constraints on $d$, then we can restrict attention to $p_{f}=p_{e}^{m}$ and $p_{e}^{m}-d=p_{d} \cdot{ }^{12}$ (4) then implies that the highest discounted price the incumbent can charge is given by $\left(p_{d}-c_{e}\right) q\left(p_{d}\right)=(1-\theta)\left(p_{e}^{m}-c_{e}\right) q\left(p_{e}^{m}\right)$. With these substitutions, we totally differentiate (4) with respect to $\theta$ to obtain:

$$
\frac{d p_{d}}{d \theta}=-\frac{\left(p_{e}^{m}-c_{e}\right) q\left(p_{e}^{m}\right)}{q\left(p_{d}\right)-\left(p_{d}-c_{e}\right) q^{\prime}\left(p_{d}\right)}
$$

We then use this in differentiating the incumbent's profit to obtain the first order condition for $\theta$ :

$$
\theta=\frac{\left(p_{d}-c\right) q\left(p_{d}\right)\left\{q\left(p_{d}\right)-\left(p_{d}-c_{e}\right) q^{\prime}\left(p_{d}\right)\right\}}{\left(p_{e}^{m}-c_{e}\right) q\left(p_{e}^{m}\right)\left\{q\left(p_{d}\right)-\left(p_{d}-c\right) q^{\prime}\left(p_{d}\right)\right\}}
$$

The right hand side of $(5)$ is increasing in $c_{e}$. At $c=c_{e}$, we get $\theta=\left(p_{d}-c\right) q\left(p_{d}\right) /\left(p_{e}^{m}-\right.$ c) $q\left(p_{e}^{m}\right)=1-\theta$, where the last equality follows from (4). This means that at $c=c_{e}$, the incumbent maximizes period 2 profits by covering half the buyers with loyalty discounts. If the entrant has a cost advantage, then the incumbent will cover a smaller fraction of the market with loyalty discounts. If the incumbent does have to be able to profitably compensate one buyer, it can do so at $c=c_{e}$ if $s(c)-s\left(p_{d}\right) \leq(N / 2)\left(p_{d}-c\right) q\left(p_{d}\right)$ where $p_{d}$ is given by $\left(p_{d}-c\right) q\left(p_{d}\right)=\left(p_{e}^{m}-c\right) q\left(p_{e}^{m}\right) / 2{ }^{13} \quad$ One might think that the incumbent would choose a larger $\theta$ because while that would reduce period 3 profits, it would reduce the amount of compensation required to ensure one buyer agrees to be covered. That isn't the case, however, because the incumbent does not have to actually pay this compensation. As long as it would be willing to compensate enough buyers, buyers will agree to be covered for no compensation because they expect the number of other buyers that will be covered will be such that uncovered buyers will pay $p_{e}^{m}$. Whereas, if they agree to be covered, they will pay $p_{d}<p_{e}^{m}$. We have now proved the following result.

\footnotetext{
${ }^{12}$ The incumbent would never want to choose a discount that did not enable to entrant to capture all uncovered buyers at its monopoly price because that would simply force the incumbent to choose a lower discounted price in order to ensure the entrant did not wish to compete for all buyers.

${ }^{13}$ This is the largest discounted price (if $c=c_{e}$ ) the incumbent can charge for which the entrant weakly prefers to sell to half the buyers at its monopoly price than to sell to all the buyers at the incumbent's discounted price.
} 
Proposition 2 If the incumbent chooses price first, it will cover a fraction of buyers $\theta \leq 1 / 2$ by a loyalty discount without buyer commitment and covered buyers will agree to be covered for no compensation if $s(c)-s\left(p_{d}\right) \leq \theta N\left(p_{d}-c\right) q\left(p_{d}\right)$ where $p_{d}$ is given by $\left(p_{d}-c_{e}\right) q\left(p_{d}\right)=(1-\theta)\left(p_{e}^{m}-c_{e}\right) q\left(p_{e}^{m}\right)$. The fraction of buyers that will be covered is increasing in $c_{e}$ and is $1 / 2$ at $c_{e}=c$. Covered buyers will pay $p_{d}$, which is strictly greater than c but strictly less than $p_{e}^{m}$. uncovered buyers will pay $p_{e}^{m}$.

Thus, if the incumbent chooses price first, then it can use loyalty discounts without buyer commitment to ensure that it makes positive profits and continues to serve a fraction of the market despite its higher costs. Whether consumers pay higher prices or not depends on what the equilibrium outcome is absent loyalty discounts, which is uncertain given that there is a continuum of equilibria.

\section{$5 \quad$ Simultaneous Pricing}

We now consider the case in which the entrant and incumbent choose their prices simultaneously in period 2. It turns out that this case has a great deal in common with the case in which the incumbent chooses price first.

With simultaneous pricing, however, the pricing equilibrium must be in mixed strategies. To see this, imagine that the entrant chose a price $p_{e}$. Then the incumbent would choose a discounted price $(p-d)$ just below $p_{e}$ in order to sell to covered buyers. The entrant's best response to such a price, however, would be either to match it or choose $p_{e}^{m}$ and sell only to uncovered buyers. Because the entrant's best response to a price just below $p_{e}^{m}$ would be to match it, there can be no pure strategy equilibrium.

We first assume that the discount, $d$, is large enough that the incumbent cannot profitably compete for buyers who did not accept the loyalty discount (uncovered buyers), even if the entrant prices at its monopoly level. We establish that this is optimal for the incumbent in the Appendix. To determine the mixed strategy equilibrium, notice that if the entrant's price distribution is given by the cumulative distribution function $F_{e}$, then the incumbent's expected period 2 profit from a discounted price of $p_{d}$ is $\theta\left(1-F_{e}\left(p_{d}\right)\right)\left(p_{d}-c\right) q\left(p_{d}\right)$. We know that the entrant will never charge a price that exceeds $p_{e}^{m}$, nor will it ever charge a price 
lower than $p_{0}$ where $p_{0}$ solves $\left(p_{0}-c_{e}\right) q\left(p_{0}\right)=(1-\theta)\left(p_{e}^{m}-c_{e}\right) q\left(p_{e}^{m}\right)$ because the entrant can always earn $(1-\theta)\left(p_{e}^{m}-c_{e}\right) q\left(p_{e}^{m}\right)$ from selling only to uncovered buyers. ${ }^{14}$ Thus, $F_{e}$ must be such that the incumbent can earn the same profit from charging $p_{d}=p_{0}$ and selling to covered buyers with probability one or charging some other $p_{d}$ and selling to covered buyers with probability $1-F_{e}\left(p_{d}\right)$. That is:

$$
\theta\left(1-F_{e}\left(p_{d}\right)\right)\left(p_{d}-c\right) q\left(p_{d}\right)=\theta\left(p_{0}-c\right) q\left(p_{0}\right)
$$

This implies that

$$
F_{e}\left(p_{d}\right)=1-\frac{\left(p_{0}-c\right) q\left(p_{0}\right)}{\left(p_{d}-c\right) q\left(p_{d}\right)}
$$

with an atom at $p_{e}^{m}$ of $\frac{\left(p_{0}-c\right) q\left(p_{0}\right)}{\left(p_{e}^{m}-c\right) q\left(p_{e}^{m}\right)}$.

If the incumbent's pricing distribution is given by the cumulative distribution function $F$, then the entrant's expected profit from charging a price of $p_{e}$ is $\theta\left(1-F\left(p_{e}\right)\right)\left(p_{e}-c_{e}\right) q\left(p_{e}\right)+$ $(1-\theta)\left(p_{e}-c_{e}\right) q\left(p_{e}\right)$. The entrant sells to all uncovered buyers as long as the discount is large enough that the incumbent's un-discounted price exceeds $p_{e}^{m}$, which the Appendix proves is always the case. The entrant sells to covered buyers with probability $1-F\left(p_{e}\right)$. The entrant can always choose a price of $p_{e}^{m}$ and obtain profits of $(1-\theta)\left(p_{e}^{m}-c_{e}\right) q\left(p_{e}^{m}\right)$ by only selling to uncovered buyers. ${ }^{15}$ That is:

$$
\theta\left(1-F\left(p_{e}\right)\right)\left(p_{e}-c_{e}\right) q\left(p_{e}\right)+(1-\theta)\left(p_{e}-c_{e}\right) q\left(p_{e}\right)=(1-\theta)\left(p_{e}^{m}-c_{e}\right) q\left(p_{e}^{m}\right)
$$

This implies that

$$
F\left(p_{e}\right)=\frac{\left(p_{e}-c_{e}\right) q\left(p_{e}\right)-(1-\theta)\left(p_{e}^{m}-c_{e}\right) q\left(p_{e}^{m}\right)}{\theta\left(p_{e}-c_{e}\right) q\left(p_{e}\right)}
$$

Notice that $p_{0}$, the minimum of both price distributions, is decreasing in $\theta$ (the condition for $p_{0}$ implies that $\left.d p_{0} / d \theta=-\left(p_{e}^{m}-c_{e}\right) q\left(p_{e}^{m}\right) /\left\{q\left(p_{0}\right)+\left(p_{0}-c_{e}\right) q^{\prime}\left(p_{0}\right)\right\}\right) ; F_{e}\left(p_{d}\right)$ is decreasing

\footnotetext{
${ }^{14}$ Since $p_{0} \geq c$, this creates a maximum $\theta$ for the mixed strategy equilibrium. For any $\theta$ above this maximum, the entrant will charge $c$ with probability one. Obviously, any $\theta$ above this maximum will not be in the interest of the incumbent, since it will earn zero profits. The maximum $\theta=1-\frac{\left(c-c_{e}\right) q(c)}{\left(p_{e}^{m}-c_{e}\right) q\left(p_{e}^{m}\right)}$.

${ }^{15}$ In equilibrium, the incumbent's maximum price cannot exceed the entrant's maximum price or the incumbent would make no profits. Thus, the entrant only sells to uncovered buyers at its maximum price. Given this, the entrant's maximum price must be $p_{e}^{m}$.
} 
in $p_{0}$ (and the atom at $p_{e}^{m}$ is increasing in $p_{0}$ ); and $F\left(p_{e}\right)$ is increasing in $\theta$. This means that the larger the fraction of covered buyers, the lower the prices (in expectation) that buyers will face from both the entrant and the incumbent. Thus, once one buyer is covered, other buyers strictly prefer to be covered than uncovered. Hence, as was the case when the incumbent chose price first, the incumbent need only be able to profitably compensate one buyer in order to induce as many buyers as it wants to be covered. In this case, however, the unique equilibrium with no covered buyers is the competitive one, so there is no doubt about the fact that the incumbent must be able to profitably compensate one buyer.

Once again, then, we simply need to determine the fraction of covered buyers that maximizes the incumbent's profits given the pricing distributions. The incumbent's expected profit is simply $\theta\left(p_{0}-c\right) q\left(p_{0}\right)$ (because he can charge $p_{0}$ and sell to all covered buyers with probability one). Using the expression for $d p_{0} / d \theta$ in the last paragraph, the first order condition for $\theta$ is:

$$
\theta=\frac{\left(p_{0}-c\right) q\left(p_{0}\right)\left\{q\left(p_{0}\right)+\left(p_{0}-c_{e}\right) q^{\prime}\left(p_{0}\right)\right\}}{\left(p_{e}^{m}-c_{e}\right) q\left(p_{e}^{m}\right)\left\{q\left(p_{0}\right)+\left(p_{0}-c\right) q^{\prime}\left(p_{0}\right)\right\}}
$$

Notice, this is the exact same condition for $\theta$ as when the incumbent chose price first (see equation (5)) with $p_{d}$ replaced by $p_{0}$. But, also notice the condition for $p_{0}$ here is identical for the condition for $p_{d}$ in the last subsection. Hence, the optimal fraction of buyers that the incumbent will choose to cover is identical (it will be exactly half if $c=c_{e}$ and less than half if the entrant has a cost advantage). The only difference between the equilibria in the two cases is that (i) the incumbent's price is higher in the simultaneous pricing case because instead of charging $p_{d}=p_{0}$ with probability one, he charges price drawn from a distribution between $p_{0}$ and $p_{e}^{m}$; and (ii) the entrant's price is lower because instead of charging $p_{e}^{m}$ with probability one, it charges a price drawn from a distribution between $p_{0}$ and $p_{e}^{m}$. Thus, uncovered buyers are better off under simultaneous pricing but covered buyers are worse off relative to the case in which the incumbent chooses price first.

Given that the incumbent's period 2 profits are identical in the two cases as is the fraction of covered buyers, we have proven the following result.

Proposition 3 If the incumbent and entrant choose price simultaneously, the incumbent will cover a fraction of buyers $\theta \leq 1 / 2$ by a loyalty discount without buyer commitment 
and covered buyers will agree to be covered for no compensation if $s(c)-s\left(p_{0}\right) \leq$ $\theta N\left(p_{0}-c\right) q\left(p_{0}\right)$ where $p_{0}$ is given by $\left(p_{0}-c_{e}\right) q\left(p_{0}\right)=(1-\theta)\left(p_{e}^{m}-c_{e}\right) q\left(p_{e}^{m}\right)$. The fraction of buyers that will be covered is increasing in $c_{e}$ and is $1 / 2$ at $c_{e}=c$. Both covered and uncovered buyers will pay a price between $p_{0}$ and $p_{e}^{m}$.

This proposition establishes that with simultaneous pricing, the incumbent can use loyalty discounts without buyer commitment to prevent the entrant from capturing the entire market, leading both to production inefficiency and prices that are elevated above the competitive level along with the associated allocation inefficiency. In fact, as we have seen, we get similar results no matter what the period 2 pricing game is. While (given the assumed market conditions) loyalty discounts without buyer commitment cannot exclude the entrant from the entire market, they can ensure that the incumbent retains positive market share (despite its relative inefficiency) and maintains supra-competitive prices.

The above proposition assumes that the incumbent has chosen a large enough discount that, in equilibrium, even if the entrant charges its monopoly price, it will sell to all uncovered buyers. We show in the Appendix that the incumbent will not choose a smaller discount that does not satisfy that property. We do this by showing that, with any discount that does not satisfy that property, there exists an equilibrium in which the incumbent earns lower profits.

\section{Conclusion}

This article has shown that loyalty discounts without buyer commitment can increase prices by producing a form of market division. The results hold for any weakly concave demand curve and even if the loyalty discount is above cost, the entrant is more efficient than the incumbent, and the loyalty discounts cover less than half the market. The results also hold even if the buyers are final consumers (or otherwise have independent demand) and can coordinate with each other. Unless the entrant cost advantage is sufficiently large, this equilibrium with anticompetitive effects will always occur if there are at least three buyers.

Morever, we prove these results even though we assume the absence of entry costs, economies of scale, buyer switching costs, financial constraints, limited rival expandabil- 
ity, and any intraproduct bundle of contestable and incontestable demand. Although prior literature suggests that loyalty discounts can have additional anticompetitive effects when those market conditions exist, this paper proves that loyalty discounts can have an important anticompetitive even without those market conditions.

These results show that the intuition that loyalty discounts presumptively reduce prices is misplaced. Loyalty "discounts" just mean there exists a difference between loyal and disloyal pricing, and thus need not signify any true discount from the but-for prices that would have existed but for the loyalty discounts. In fact, because the existence of loyalty discounts changes the strategic game between the buyer and the seller, we show that loyalty discounts encourage incumbents to raise prices above but-for levels for both free buyers and buyers who receive the loyalty discount.

Our results have important implications for how competition policy should treat loyalty discounts without buyer commitments. First, such loyalty discounts can be anticompetitive even when they are above cost. Indeed, raising even the loyal prices above but-for levels (and thus well above cost) is precisely the anticompetitive effect. Second, such loyalty discounts can be anticompetitive when they cover only a minority of buyers. In fact, covering a minority of buyers is part the incumbent's optimal anticompetitive strategy under simultaneous pricing or if the incumbent prices first. Third, loyalty discounts can be anticompetitive without showing the sorts of market conditions (like economies of scale or intermediary buyers) that may be necessary to show that exclusive dealing is anticompetitive. Fourth, loyalty discounts can also be anticompetitive without the sorts of market conditions (like switching costs or intraproduct bundling of contestable and incontestable demand) that past models have used to explain how loyalty discounts without buyer commitment can have exclusionary anticompetitive effects.

Our model assumes that the incumbent only offers a discount off a price to be determined later. We explained above, in footnote 7, why specifying price in advance might not be possible (this is the standard assumption in the exclusive dealing literature). Moreover, since the incumbent is not requiring buyers to commit to buying from it, it is natural that it would not need to commit to a price at this time. Evn if the incumbent could offer a contract that specified price in advance, this would not be as profitable for the incumbent 
unless the contract somehow linked the price it offered to loyal buyers to the price if offered to disloyal buyers. It is this linking of price that creates the externality across buyers that allows the incumbent to retain market share and earn profits even though this reduces total welfare. If the incumbent could credibly commit to a price to both loyal buyers and disloyal buyers, then it would commit to charge disloyal buyers a price above the entrant's monopoly price and charging loyal buyers the same price, $p_{d}$, as in Proposition 2 when the incumbent chooses price first. We then get the exact same equilibrium as in Proposition 2.

Two limitations should be stressed. First, we have assumed a market with only one potential rival. This can often be the case, especially in high-tech or pharmaceutical markets, but if there were multiple rivals with similar costs it is possible they would compete prices down to their costs. However, the same sort of analysis seems likely to apply to the extent only one entrant has a potential cost advantage and the other rivals have higher costs and merely provide a competitive fringe. Multiple rivals might also use loyalty discounts themselves, creating similar or even exacerbated market segmentation effects. ${ }^{16}$ But it remains for future work to extend the model here to cases involving multiple rivals or where multiple firms use loyalty discounts. ${ }^{17}$

Second, we have assumed loyalty discounts have no efficiencies. If they did, those might offset any adverse effects. It seems likely the present model can be extended to show how much of a cost reduction would be necessary to offset the anticompetitive effects, but that also remains a matter for future work.

\section{Appendix}

Proof of Proposition 1. (A) By choosing an arbitrarily large $d$, the incumbent can guarantee that (1) is satisfied at $p_{e}^{m}$ for any $\theta>0$. Thus, the incumbent will respond to the entrant's price of $p_{e}^{m}$ by offering $p_{f}=p_{e}+d-\varepsilon$ and selling only to covered buyers. The entrant will choose $p_{e}^{m}$ rather than $c$ (which would enable it to sell to all buyers) as long as $\theta \leq \bar{\theta}$. Thus, the incumbent's can maximize its profit by getting $\bar{\theta} N$ buyers to be covered

\footnotetext{
${ }^{16}$ See Elhauge (2009) at pp. 195, 214-15 for a discussion of these issues.

${ }^{17}$ See Kitamura (2010) for an argument that naked exclusion is less effective if there are multiple entrants.
} 
by the discount. It only remains to show that these buyers will accept the discount for an arbitrarily small payment. To show this, consider the case in which $N-\bar{\theta} N$ buyers have rejected the incumbent's offer. If the next buyer believes that all future buyers will also reject, then she will accept the discount if she is paid $s(c)-s\left(p_{e}^{m}\right)$, her loss of consumer surplus from paying a price of $p_{e}^{m}$ rather than $c$. Because (1) can be satisfied at $p_{e}^{m}$ for large enough $d$ even after only one buyer has signed, all subsequent buyers know that their decision to be covered will not affect equilibrium prices. So, none of these buyers need more than a trivial payment to accept the discount. Thus, even if $N-\bar{\theta} N$ buyers have already rejected the incumbent's discount, the incumbent can get the remaining buyers covered with only a total payment of $s(c)-s\left(p_{e}^{m}\right)$. This is profitable so long as $s(c)-s\left(p_{e}^{m}\right)<\bar{\theta} N\left(\left(p_{e}^{m}-c\right) q\left(p_{e}^{m}\right)\right)$. This never holds if $\bar{\theta} N<2$. Because the first $N-\bar{\theta} N$ expect the incumbent to sign $\bar{\theta} N$ buyers even if they reject the incumbent's offer, rejecting the offer does not increase their consumer surplus. Hence, the first buyer approached will accept being covered for only a trivial side-payment, which means that all subsequent buyers approached will also.

(B) First, we define the following terms to simplify the later notation. Let $\pi_{E}^{m}=$ $\left(p_{e}^{m}-c_{e}\right) q\left(p_{e}^{m}\right)$ be the entrant's monopoly profit per buyer. Let $\pi_{E}^{c}=\left(c-c_{e}\right) q(c)$ be the entrant's profit per buyer if it charges a price of $c$. Let $\pi^{p_{e}^{m}}=\left(p_{e}^{m}-c\right) q\left(p_{e}^{m}\right)$ be the incumbent's profit per buyer it serves at the entrant's monopoly price. Let $\pi^{0}=c q(0)$ be the incumbent's loss per buyer it serves at a price of zero.

If the incumbent cannot charge a negative price, then the maximum loss it can suffer from selling to covered buyers is $c q(0)$. Given this, the entrant will choose $p_{e}^{m}$ if and only if the fraction of covered buyers is at least $\hat{\theta}$ but less than $\bar{\theta}$. Thus, once the incumbent has $\hat{\theta} N$ covered buyers, all remaining buyers up until $\bar{\theta} N$ do not require compensation to be covered because they will pay the same price, $p_{e}^{m}$, whether they are covered or not because the entrant will offer a price of $p_{e}^{m}$ once there are $\hat{\theta} N$ covered buyers but not more than $\bar{\theta} N$ covered buyers. We will assume the worst case for making such compensation profitable. Specifically, we will ask if the incumbent can obtain agreement to be covered from $\bar{\theta} N$ buyers when $N-\bar{\theta} N$ buyers have already rejected the offer. We will then assume that remaining buyers believe that if they reject the incumbent's offer, then all future buyers will reject, but if they accept, then enough buyers will accept ( $\hat{\theta} N$ buyers) so that they will face a price 
of $p_{e}^{m}$. Lastly, contrary to fact, we will assume that even when some buyers have already accepted, until $\hat{\theta} N$ buyers have accepted, the buyers believe that rejecting the offer will enable them to buy at the competitive price of $c$. We make this assumption simply because for a general demand curve, we cannot get an explicit formula for $\overline{p_{e}}$ as a function of the number of buyers who have already accepted. Thus, $\hat{\theta} N$ buyers must receive compensation of $s(c)-s\left(p_{e}^{m}\right)$.

This means it is profitable for the incumbent to get $\bar{\theta} N$ buyers to accept if:

$$
\bar{\theta} N \pi^{p_{e}^{m}}-\hat{\theta} N\left(s(c)-s\left(p_{e}^{m}\right)\right)>0
$$

Substituting for $\bar{\theta}$ and $\hat{\theta}$, we can write this as:

$$
\frac{\pi_{E}^{m}-\pi_{E}^{c}}{\pi_{E}^{m}} \pi^{p_{e}^{m}}-\frac{\pi^{p_{e}^{m}}}{2 \pi_{e}^{p_{e}^{m}}+\pi^{0}}\left(s(c)-s\left(p_{e}^{m}\right)\right)>0
$$

We know that $s(c)-s\left(p_{e}^{m}\right)=\int_{c}^{p_{e}^{m}} q(x) d x<\left(p_{e}^{m}-c\right) q(c)$. Thus, a sufficient condition is:

$$
\left(\pi_{E}^{m}-\pi_{E}^{c}\right)\left(2 \pi^{p_{e}^{m}}+\pi^{0}\right)-\pi_{E}^{m}\left(p_{e}^{m}-c\right) q(c)>0
$$

It is easy to see that if the entrant's innovation is almost drastic (so that $p_{e}^{m}$ is only slightly larger than $c), \pi_{E}^{m}-\pi_{E}^{c}$ close to zero, then this sufficient condition will not hold. On the other hand, if the entrant's cost advantage is very small, $\pi_{E}^{c}$ almost zero and $\pi^{p_{e}^{m}}$ is almost as big as $\pi_{E}^{m}$, then this is $\pi_{E}^{m}\left[\pi^{0}+\left(p_{e}^{m}-c\right)\left(2 q\left(p_{e}^{m}\right)-q(c)\right)\right]$. This is always positive if $q$ is concave because the monopoly quantity exceeds half the competitive quantity for concave demand.

As in (A), because the first $N-\bar{\theta} N$ expect the incumbent to sign $\bar{\theta} N$ buyers even if they reject the incumbent's offer, rejecting the offer does not increase their consumer surplus. Hence, the first buyer approached will accept being covered for only a trivial side-payment, which means that all subsequent buyers approached will also.

(C) This follows from the proof of (B) because this proof continues to be valid if we take $\pi^{0}=0$, as would be the case if the discounted price equals the incumbent's cost. Q.E.D.

\section{Proof that large discount is optimal in section 5}


Next, we show that in the simultaneous pricing case without commitment, that the incumbent will choose a large enough discount so that it will not sell to uncovered buyers in equilibrium. First, note that if $\left(c-c_{e}\right) q(c) \geq(1-\theta)\left(c+d-c_{e}\right) q(c+d)$, then there exists a pure strategy equilibrium in which $p_{e}=p_{d}=c$ and the entrant captures the entire market. Such an equilibrium is obviously less profitable to the incumbent than the large $d$ equilibrium. This equilibrium exists when $d$ is very small.

The large $d$ equilibrium described above requires that the incumbent does not want to deviate by choosing a discounted price of $p_{e}^{m}-d$ in order to sell to uncovered buyers at $p_{e}^{m}$ in the event that the entrant charges $p_{e}^{m}$ (and to all covered buyers with probability one at $\left.p_{e}^{m}-d\right)$. This deviation is not profitable if and only if:

$$
(2 \theta-1)\left(p_{0}-c\right) q\left(p_{0}\right)-\theta\left(p_{e}^{m}-d-c\right) q\left(p_{e}^{m}-d\right) \geq 0
$$

because $\theta \leq 1 / 2$, this equilibrium requires that $d>p_{e}^{m}-c$.

It is easy to see that there may exist an intermediate $d$ such that neither of these two equilibria exist. For example, if $c=c_{e}$, the pure strategy equilibrium does not exist for any $d>0$ and yet the large $d$ mixed strategy equilibrium will not exist for $d<p_{e}^{m}-c$. In this intermediate case, we construct a mixed strategy equilibrium of the same type as the equilibrium with a large discount. The key difference is that the top price charged with positive probability, which we will call $p_{T}$, and the bottom price charged, $p_{B}$, must be smaller to satisfy the no deviation condition. $\quad p_{T}$ and $p_{B}$ still satisfy $\left(p_{B}-c_{e}\right) q\left(p_{B}\right)=$ $(1-\theta)\left(p_{T}-c_{e}\right) q\left(p_{T}\right)$, so that the entrant is indifferent between selling only to uncovered buyers (with probability one) at $p_{T}$ and selling to all buyers (with probability one) at $p_{B} \cdot{ }^{18}$ The entrant's price distribution is given by $F_{e}\left(p_{d}\right)=1-\frac{\left(p_{B}-c\right) q\left(p_{B}\right)}{\left(p_{d}-c\right) q\left(p_{d}\right)}$ with an atom at $p_{T}$ of $\frac{\left(p_{0}-c\right) q\left(p_{0}\right)}{\left(p_{T}-c\right) q\left(p_{T}\right)}$. The incumbent's distribution is given by $F\left(p_{e}\right)=\frac{\left(p_{e}-c_{e}\right) q\left(p_{e}\right)-(1-\theta)\left(p_{T}-c_{e}\right) q\left(p_{T}\right)}{\theta\left(p_{e}-c_{e}\right) q\left(p_{e}\right)}$. The analysis above shows that these distributions guarantee that both the incumbent and the entrant are indifferent between charging any (discounted for the incumbent) price in the interval between $p_{B}$ and $p_{T}$.

\footnotetext{
${ }^{18}$ Once again, since $p_{B} \geq c$, this creates a maximum $\theta$ for this mixed strategy equilibrium. For any $\theta$ above this maximum, the entrant will charge $c$ with probability one. The maximum $\theta=1-\frac{\left(c-c_{e}\right) q(c)}{\left(p_{T}-c_{e}\right) q\left(p_{T}\right)}$. Clearly, this maximum is smaller than the above maximum with large $d$ since $p_{T}<p_{e}^{m}$.
} 
When the discount is small, however, it remains to show that the incumbent does not want to deviate to a discounted price of $p_{T}-d$ in order to sell to uncovered buyers at $p_{T}$ in the event that the entrant charges $p_{T}$ (and to all covered buyers with probability one at $\left.p_{T}-d\right)$. The incumbent's expected profit from charging a discounted price of $p_{T}-d$ :

$$
(1-\theta) \frac{\left(p_{B}-c\right) q\left(p_{B}\right)}{\left(p_{T}-c\right) q\left(p_{T}\right)}\left(p_{T}-c\right) q\left(p_{T}\right)+\theta\left(p_{T}-d-c\right) q\left(p_{T}-d\right)
$$

This deviation is not profitable if and only if:

$$
(2 \theta-1)\left(p_{B}-c\right) q\left(p_{B}\right)-\theta\left(p_{T}-d-c\right) q\left(p_{T}-d\right) \geq 0
$$

If $\theta<1 / 2$, it is easiest to deter deviation with $p_{B}=c$. In that case, deviation is not profitable if and only if $p_{T} \leq c+d$. If this does not hold, then thee equilibrium in which $p_{e}=p_{d}=c$ and the entrant captures the entire market exists. So, whenever this equilibrium does not exist, we can deter deviation from this mixed strategy equilibrium by choosing $p_{B}=c$ and $p_{T}$ given by $\left(c-c_{e}\right) q\left(p_{B}\right)=(1-\theta)\left(p_{T}-c_{e}\right) q\left(p_{T}\right)$. While this equilibrium may also exist (it may be possible to deter deviation) for $p_{B}>c$, we must have $p_{B}<p_{0}$ and $p_{T}<p_{e}^{m}$ or else we are in the large $d$ equilibrium. As a result, this equilibrium is less profitable for the incumbent than the large $d$ equilibrium.

It is worth pointing out that the equilibrium in this case is different from the equilibrium described in Elhauge (2009) for simultaneous pricing without commitment and a small discount. In Elhauge's proposed equilibrium, the incumbent could profitably deviate by charging a discounted price just below the support of his distribution that allows him to sell to uncovered buyers with non-zero probability because the entrant has an atom in its distribution at its highest price.

\section{References}

[1] Aghion, Philippe, and Patrick Bolton. 1987. "Contracts as a Barrier to Entry." American Economic Review, 77(3): 388-401. 
[2] Argention, Cedric. 2010. "Exclusive Quality." Journal of Industrial Economics, 58:690716.

[3] Bernheim, B. Douglas, and Michael D. Whinston. 1998. "Exclusive Dealing." Journal of Political Economy, 106(1): 64-103.

[4] Butz, David A. 1990. "Durable-Good Monopoly and Best-Price Provisions," American Economic Review 80: 1062-76.

[5] Chen, Zhijun and Greg Shaffer. 2010. "Naked Exclusion with Minimum Share Requirements," Working Paper.

[6] Cooper, Thomas E. 1986. "Most-Favored-Customer Pricing and Tacit Collusion," The RAND Journal of Economics 17: 377-388.

[7] Edlin, Aaron. 1997. "Do Guaranteed-Low-Price Policies Guarantee High Prices, and Can Antitrust Rise to the Challenge?", Harvard Law Review 111: 528-575.

[8] Elhauge, Einer. 2003. "Defining Better Monopolization Standards." Stanford Law Review 56: 253-344.

[9] Elhauge, Einer. 2008. United States Antitrust Law \& Economics. Foundation Press: New York.

[10] Elhauge, Einer. 2011. United States Antitrust Law \& Economics, 2d. ed.. Foundation Press: New York.

[11] Elhauge, Einer. 2009. "How Loyalty Discounts Can Perversely Discourage Discounting," Journal of Competition Law \& Economics 5: 189-231.

[12] Elhauge, Einer and Abraham L. Wickelgren. 2012. "Robust Exclusion Through Loyalty Discounts," Mimeo.

[13] Farrell, Joseph. 2005. "Deconstructing Chicago on Exclusive Dealing," Antitrust Bulletin 50: 465-480 (2005). 
[14] Fumagalli, Chiara, and Massimo Motta. 2006. "Exclusive Dealing and Entry, when Buyers Compete." American Economic Review, 96(3):785-95.

[15] Hovenkamp, Herbert. 2005. Antitrust Law Vol.. XI (2d ed.).

[16] Hovenkamp, Herbert. 2006. "Discounts and Exclusion." Utah Law Review, 2006: 841861.

[17] Hviid, Morten and Greg Shaffer. 2010. "Matching Own Prices, Rivals' Prices or Both?" Journal of Industrial Economics, 58:479-506.

[18] Innes, Robert, and Richard J. Sexton. 1994. "Strategic Buyers and Exclusionary Contracts." American Economic Review, 84(3): 566-84.

[19] Kaplow, Louis \& Carl Shapiro. 2007. "Antitrust," in Handbook of Law \& Economics 2: 1073-1225 (eds. Polinsky \& Shavell).

[20] Kitamura, Hiroshi. 2010. "Exclusionary Vertical Contracts with Multiple Entrants." International Journal of Industrial Organization, 28:213-219.

[21] Kolay, Sreya, Greg Shaffer, and Janusz A. Ordover. 2004. "All-Units Discounts in Retail Contracts," Journal of Economics and Management Strategy, 13:429-459.

[22] Lambert, Thomas A.. 2005. "Evaluating Bundled Discounts." Minnesota Law Review, 89: $1688-1757$.

[23] Lin, Y. Joseph. 1990. "The Dampening of Competition Effect of Exclusive Dealing," Journal of Industrial Economics, 39:209-223.

[24] Mahenc, Philippe and Francois Salanie. 2004. "Softening Competition Through Forward Trading," Journal of Economic Theory, 116:282-293.

[25] Marx, Leslie M. \& Greg Shaffer. 2004. "Opportunism in Multilateral Vertical Contracting: Nondiscrimination, Exclusivity, and Uniformity: Comment," American Economic Review 94: 796-801. 
[26] Marx, Leslie M. \& Greg Shaffer. 2004. "Rent-Shifting, Exclusion, and Market-Share Discounts," Working Paper.

[27] Mathewson, G. Frank, and Ralph A. Winter. 1987. "The Competitive Effects of Vertical Agreements: Comment." American Economic Review, 77(5): 1057-62.

[28] Neeman, Zvika. 1999. "The Freedom to Contract and the Free-Rider Problem." Journal of Law, Economics, and Organization, 15(3): 685-703.

[29] Ordover, Janusz and Greg Shaffer. 2007. "Exclusionary Discounts," Working Paper.

[30] Rasmusen, Eric B., J. Mark Ramseyer, J., and John S, Wiley. 1991. "Naked Exclusion", American Economic Review, 81(5):1137-45.

[31] Rey, Patrick and Joseph E. Stiglitz. 1995. "The Role of Exclusive Territories in Producers' Competition," The RAND Journal of Economics 26: 431-451.

[32] Schnitzer, Monika. 1994. "Dynamic duopoly with best-price clauses," The RAND Journal of Economics 25: 186-196.

[33] Segal, Ilya R., and Michael Whinston. 2000. "Naked Exclusion: Comment." American Economic Review, 90: 296-309.

[34] Simpson, John and Abraham L. Wickelgren. 2007. "Naked Exclusion, Efficient Breach, and Downstream Competition." American Economic Review, 97: 1305-1320.

[35] Spector, David. 2005. "Loyalty Rebates: An Assessment of Competition Concerns and a Proposed Structured Rule of Reason," Competition Policy International 1(2): 89-114 (Autumn).

[36] Tom, Willard K., David A. Balto \& Neil W. Averitt. 2000. "Anticompetitive Aspects of Market-Share Discounts and Other Incentives to Exclusive Dealing," Antitrust L.J. 67: 615 .

[37] Whinston, Michael D. 2006. Lectures on Antitrust Economics (2006). 
[38] Wright, Julian. 2008. "Naked Exclusion and the Anticompetitive Accomodation of Entry," Economics Letters, 98:107-112. 